\title{
Rolando Pantoja Bauzá ${ }^{1}$
}

Ciertamente, cuando nos toca experimentar la despedida de un ser querido, como lo fue Rolando para quienes estamos aquí, el análisis racional que nos hace aceptar con resignación nuestra mortalidad, choca y cala hondo en lo profundo de nuestros sentimientos, donde reside el afecto, cariño, apego, consideración. Es entonces cuando el pesar nos atrapa.

Hoy, con pesar, despedimos a un destacado académico, a un estrecho colaborador, a un gran administrativista y hombre de Derecho. Despedimos a una persona con la cual cultivamos una amistad, basada en una relación de respeto, admiración y lealtad.

Rolando se merece con creces un lugar en nuestros recuerdos y en el de decenas de generaciones que formó como profesor titular de la cátedra de Derecho Administrativo en la Facultad de Derecho de la Universidad de Chile, siendo también primera antigüedad de dicha cátedra en el plano nacional.

Al igual que muchos de nosotros, que llevamos grabada a fuego nuestra Universidad de Chile, Rolando fue un académico de carrera, desarrollándola paso a paso, con dedicación, esfuerzo y vocación. Primero como alumno ayudante de cátedra, logrando más tarde ser investigador del Seminario de Derecho Público. Tras cursar sus estudios de pregrado y titularse de abogado su espíritu inquieto lo llevó a obtener más tarde un doctorado en Derecho en la Universidad de Madrid.

Su roce internacional y logros no nublaron su amor genuino por la Universidad de Chile. Continuó su carrera como profesor de Derecho Administrativo de Pre y Postgrado. Ocupó las direcciones del Departamento de Derecho Público y de la Escuela de Derecho. Fue también Vicedecano de la Facultad, Director del Magíster en Derecho con mención en Derecho Público que la Facultad desarrolló en Talca y presidente de comisiones de Licenciatura y miembro de número de las comisiones de Calificación Académica, de Evaluación Académica y de Ética Académica. Por sus conocimientos y sapiencia también ejerció la labor de Director General Jurídico de la Universidad de Chile.

Destacó también en el plano profesional, como abogado de la División Jurídica y jefe de estudios de la Contraloría General de la República, institución en la que ocupó el primer lugar en el escalafón directivo. Bajo la presidencia de Eduardo Frei Ruiz-Tagle, fue asesor externo del Ministerio Secretaría General de la Presidencia, encargado de la redacción y tramitación en el Congreso Nacional de la Ley No 19.653 de Probidad de los Órganos de la Administración Pública.

Integró diversas organizaciones en las que compartió con destacados juristas iberoamericanos, siendo parte de un selecto grupo. En este contexto, fue presidente del Instituto Chileno de Derecho Administrativo e integrante de la Asociación Internacional de

Palabras de despedida al profesor Rolando Pantoja Bauzá, pronunciadas por el Decano de la Facultad de Derecho de la Universidad de Chile, profesor Roberto Nahum Anuch, en los funerales celebrados el domingo 9 de junio de 2013 .

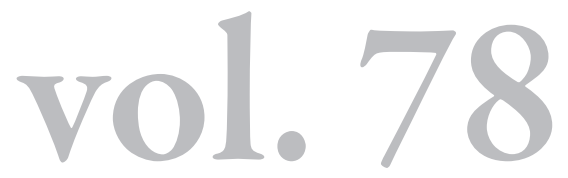


Derecho Administrativo, con sede en México, y del Foro Iberoamericano de Derecho Administrativo, en España.

Pero su aporte va más allá del aula y del ejercicio profesional. Como jurista e intelectual de fuste fue autor de célebres obras, como "Estatuto Administrativo Interpretado", libro de consulta obligada en las distintas reparticiones públicas que conforman la administración del Estado.

Su prolífica pluma, por cierto, no se limitó a ese verdadero baluarte del Derecho Administrativo. Dio vida a otras publicaciones como "Derecho Administrativo. Clasicismo y modernidad", "Organización Administrativa del Estado de Chile", "Derecho Administrativo. Características, prospección”. Todas bajo el sello de Editorial Jurídica de Chile.

Se suman a ellas otras de más reciente data, de cortes internacionales, históricoconmemorativos y enciclopédicos, como "Derecho Administrativo Chileno", nacida en 2007 al alero de la Universidad Nacional Autónoma de México y editada por la Editorial Porrúa de dicho país. Participó como coautor, director y coordinador académico de "Derecho Administrativo. 120 ańos de cátedra", lanzado en 2008 y "Derecho Administrativo. 150 años de doctrina”, presentado un año más tarde.

En 2010, con el patrocinio de la Facultad de Derecho de la Universidad de Chile y de la Comisión Nacional Bicentenario, publicó el Tomo I del "Tratado de Derecho Administrativo", obra en ocho tomos sobre "Derecho y Administración del Estado".

Perdemos, de esta manera, a un gran jurista, intelectual, autor, profesor, profesional y amigo. Sin duda hombres como Rolando Pantoja reflejan en plenitud el ser universitario y son ejemplos imborrables de las futuras generaciones.

Rolando, amigo, donde quiera que estés, recibe nuestra gratitud, respeto y cariño. Siempre ocuparás un lugar en nuestros corazones y recuerdos. Gracias por todo lo que entregaste, por la lealtad hacia la institución y, de manera especial, hacia mi persona. No hay palabras, sólo me embarga la congoja al recordar las muchas luchas que dimos juntos, codo a codo, esos momentos difíciles en los que resaltan los hombres auténticos, los valientes.

Gracias Rolando, descansa. Tu legado está vivo, en tus obras, en nuestros recuerdos y en tus orgullosos discípulos.

Roberto Nahum Anuch

Decano

Facultad de Derecho

Universidad de Chile 